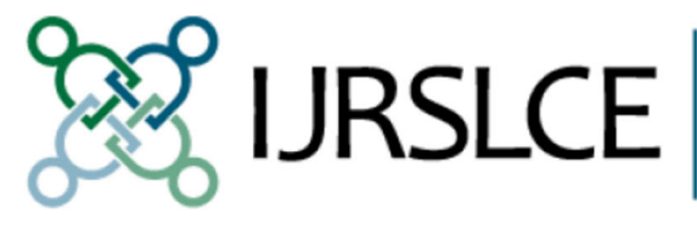

International Journal

for Research on

Service-Learning \&

Community Engagement

\title{
The Impacts of Undergraduate Service- Learning on Post-Graduation Employment Outcomes
}

\author{
Paul H. Matthews \\ Jeffery H. Dorfman \\ Xuedong Wu
}

This article was originally published at:

https://journals.sfu.ca/iarslce/index.php/journal/article/view/109/71

Recommended Citation

Matthews, P. H., Dorfman, J. H., \& Wu, X. (2015). The impacts of undergraduate servicelearning on post-graduation employment outcomes. International Journal of Research on Service-Learning and Community Engagement, 3(1), Article 18. 


\title{
The Impacts of Undergraduate Service-Learning on Post-Graduation Employment Outcomes
}

\author{
Paul H. Matthews \\ Jeffrey H. Dorfman \\ Xuedong Wu \\ University of Georgia
}

\begin{abstract}
This article highlights the results of a study assessing service-learning's impact on post-graduation employment for students from a large, public land-grant university who had completed their undergraduate degree. Survey data collected three years after graduation yielded 44 unique pairs matched for undergraduate major, graduation date, gender, and academic performance, but with only a single member of each pair having taken service-learning coursework. The study investigated employment outcomes including time needed to find a first job, starting salary, timing of promotions and raises, and type of employment. Paired t-tests found significantly higher starting salaries and significantly shorter time to receive a first raise for graduates with service-learning experience. No significant differences were found regarding (a) whether either set received a raise or promotion, (b) whether the job was in their desired field, (c) the overall time to find an initial job, or (d) the length of time from hiring to first promotion. These results represent the first empirical data assessing service-learning's potential influence on economic aspects of post-university employment.
\end{abstract}

Keywords: service-learning, post-graduation employment, matched pairs, salary, post-graduation impacts

Do college graduates who have taken part in academic service-learning improve their employment prospects as a result of these experiences? Against the national backdrop of high unemployment, rising tuition, and increasing student debt for graduates, stakeholders-including students, institutions, parents, lawmakers, and others-are increasingly interested in higher education's economic impacts and, specifically, the perceived "value" of an undergraduate degree (e.g., Newman, 2014; Webber, 2014). Academic service-learning, a high-impact educational practice (Kuh, 2008), has an ongoing research record that clearly establishes its benefits across student learning outcomes in academic, civic, and personal realms. The experiential focus of service-learning has also been hypothesized to have outcomes that might result in employment-related benefits. For instance, Duncan and Taylor (2013) note:

In a world of inflated grades and the consequent academic excellence of so many graduates, graduate schools and businesses are beginning to examine other qualifications of their applicants. Many rate service to the community high on the list of what separates the average applicant from the superior one not only [due] to the commitment it requires but also the skills it can produce that are frequently not acquired in a classroom. (p. 3)

Might employers thus give tangible preference to graduates who have improved mastery of their course content from service-learning, and who presumably possess enhanced professional and personal skills such as time management, teamwork, and leadership? Some service-learning opportunities may also 
provide students with direct professional experiences that could make them more competitive as job candidates. While such claims are not uncommon in relation to service-learning, no specific hypotheses have been directly assessed to date.

\section{College Influences on Employment and Earnings Outcomes for Graduates}

Post-secondary education - especially degree completion-strongly impacts both short- and long-term employment-related outcomes for students. Indeed, long-term benefits of higher education "include higher lifetime earnings, a more fulfilling work environment, better health, longer life, more informed purchases, and lower probability of unemployment" (Perna, 2005, p. 24). As Pascarella (2006) has noted, most research on the contributions of higher education has focused on linking macro-level features such as degree attainment to "such long-term outcomes as earnings, labor-market success, health status, ... civic involvement, continuing education, and the like," with less attention given to "specific withincollege academic and nonacademic experiences" (p. 516). However, beyond the impact of degree completion itself, a number of other factors also appear to influence college graduates' salaries and employment outcomes.

$\mathrm{Hu}$ and Wolniak (2010) summarized research from economics and sociology investigating how the particular components of a college education-such as majors or institutional type-influence economic and employment outcomes. For instance, graduates' major or field of study reportedly accounts for 25$30 \%$ of differences in their post-college earnings (Pascarella \& Terenzini, 2005, as cited in $\mathrm{Hu} \&$ Wolniak, 2010, p. 752); similarly, other recent studies (e.g., Carnevale, Cheah, \& Hanson, 2015; Webber, 2014) have found large lifetime earnings differences based on graduates' ability and their particular field of study.

Research on the impacts of fixed student-level factors such as race, gender, and family income has produced "equivocal" results (Perna, 2005, p. 26). Hu and Wolniak $(2010,2013)$ reviewed research on the differential impacts of college experiences by group, noting some differential outcomes for men and women, as well as for students from lower income backgrounds and from different racial and ethnic groups. Specifically, these authors investigated the early career (i.e., five years after high school completion) earnings of ethnic minority students who had applied to the Gates Millennium Scholars program. Their analysis was based on self-reports of students' college "academic engagement" (i.e., frequency of working or discussing academic content outside of class) and their "social engagement" (i.e., levels of participation in cultural, Greek, and community service events). Hu and Wolniak found that males reported higher annual earnings but did not find salary differences across ethnic groups. Additionally, these graduates' early career earnings differed significantly based on student academic preparation (based on SAT/ACT scores), with those in the lowest group also reporting the lowest earnings. The researchers' regression analyses also found differing effects of academic and social engagement by gender, ethnicity, and major field (STEM vs. non-STEM). However, while Hu and Wolniak's studies included reports of frequency of participation in community service activities, no published research has specifically investigated the relationship between employment and earnings outcomes, and the experiences associated with academic service-learning in college.

\section{Service-Learning's Outcomes and Impacts}

Academic service-learning courses engage students in applying their learning to real-world, communityidentified problems or issues. Service-learning's key components include relevant service, a range of possible learning goals, reflection, and reciprocity, as illustrated in Bringle and Hatcher's (1995) definition of academic service-learning as 
a course-based, credit-bearing educational experience in which students participate in an organized service activity that meets identified community needs, and reflect on the service activity in such a way as to gain further understanding of course content, a broader appreciation of the discipline, and an enhanced sense of personal values and civic responsibility. (p. 112)

Decades of research across a range of disciplines and institutional contexts has shown this pedagogy's positive effects on student academic learning outcomes (Clayton, Bringle, \& Hatcher, 2013; Eyler \& Giles, 1999; Eyler, Giles, Stenson, \& Gray, 2001). For instance, Jameson, Clayton, and Ash (2013) summarized research relating to service-learning's impacts on academic learning outcomes, finding particular benefit to higher order thinking skills, application of knowledge, and critical thinking. Similarly, in her meta-analysis of 11 research studies, Warren (2012) found a significant impact of service-learning on a host of student learning outcomes, with an overall effect size of $d=.332$. Indeed, in analyses published by the Association of American Colleges and Universities, service-learning has been touted as one of the "high-impact educational practices" (Brownell \& Swaner, 2010; Kuh, 2008) that have resulted consistently in positive student learning outcomes. Recent research also suggests that students taking part in service-learning courses have a higher level of degree completion than peers without such coursework (Lockeman \& Pelco, 2013).

In addition to academic learning outcomes, educational research has investigated and demonstrated other impacts of service-learning such as personal identity development, enhanced moral reasoning, critical thinking, citizenship, intercultural competence, and other civic and personal benefits (Clayton, Bringle, \& Hatcher, 2013; Eyler \& Giles, 1999). However, little research has specifically focused on service-learning's influences on students' future employment. While longer term impacts are mostly unknown, some evidence suggests that students who engage in service in college tend to be more interested in and more involved in service activities after graduation (Astin, Sax, \& Avalos, 1999). Service activities, including those undertaken through service-learning courses, can help students confirm their choice of major (Sledge, Shelburne, \& Jones, 1993) and may change students' self-reported attitudes or interest toward particular careers such as teaching (McElhaney, 1998; Tartter, 1996). Taking part in service-learning has also been shown to have some influence on what careers students actually choose (Smedick, 1996; Smith Korfmacher, 1999; Warchal \& Ruiz, 2005), helping for instance to promote careers that also entail public service (Astin, Vogelgesang, Ikeda, \& Yee, 2000; Fenzel \& Peyrot, 2005; Vogelgesang \& Astin, 2000).

Fenzel and Peyrot (2005) reviewed and conducted research on post-graduation impacts of undergraduate involvement in community service and service-learning for alumni from a Catholic liberal arts college. Though they did not conduct a matched-pair analysis, they found that a significantly higher percentage of those with service-learning (37.2\%) reported holding a job in a "service field"operationalized as "education, nonprofit, government, health care, [or] social work" (p. 26) - than did those with no undergraduate service experiences (26.5\%). As jobs in such fields are traditionally considered to pay lower wages than the private sector, perhaps this preference for service-oriented careers could lead to salary differences across groups and thus be at least partially a result of their involvement in service-learning. (While not investigating service-learning, $\mathrm{Hu}$ and Wolniak [2013] hypothesized a similar possibility for some students in their sample, suggesting that those "who are more socially engaged on campus are more committed to social issues and thus choose careers with more service orientation but lower financial returns" [p. 228].)

Conversely, however, the hands-on, experientially oriented nature of service-learning might give students experiences that could also help them find jobs more rapidly or at higher wages. Internships, which similarly provide direct, hands-on experience within a particular field, are frequently cited as leading to higher rates of job offers for students; yet, a recent analysis by the National Association of Colleges and Employers found "no significant difference between those with an internship and those without an internship in receiving a job offer once those graduates who received a direct offer from the internship [were] eliminated" (Koc, 2014). 
The "soft skills" that students develop in service-learning placements may also impact their employability. For instance, Eyler and colleagues (2001) summarized research indicating that "servicelearning has a positive effect on ... the ability to work well with others, leadership and communication skills" (p. 1) - presumably attributes that many employers seek in prospective employees. In fact, in surveys of employers in the business and nonprofit sectors, critical thinking, communication, problemsolving, intercultural skills, and "applied knowledge in real-world settings" top the list of competencies they report looking for in job candidates (Sternberg, 2013). As each of these competencies has been demonstrated to be potentially enhanced through academic service-learning experiences, it seems plausible that such experiences might benefit students in the job market. However, little empirical evidence exists in support of actual associations between service-learning experiences and postgraduation employment and salaries.

In estimates summarized in a poster presentation (Overby, 2011) and in an unpublished manuscript (Overby, Latham, Lewis, \& Serra, n.d.), researchers at the University of Delaware attempted to "measure the economic value of community engagement" (Overby et al., n.d., p. 2) for course-based and cocurricular service. In addition to calculating an estimated hourly dollar value for student service contributions, including multiplier effects for indirect expenditures and induced spending, the researchers also posited and assigned economic value to service-learning, suggesting several potential mechanisms for enhancement (pp.14-15) - first, that the experience would signal to employers that these graduates would bring valuable skills and attitudes, resulting in a speedier initial employment; that such graduates would be offered higher starting salaries; and that such employees would then be given more rapid opportunities for career advancement (i.e., raises and promotions). Although the investigators assigned and extrapolated tentative percentage boosts and dollar values to these hypothesized differences, their study did not attempt to demonstrate actual career enhancements from service-learning.

The current study was undertaken to begin testing research questions around the impacts that participation in academic service-learning actually has on later employment. Specifically, it was designed to investigate whether university graduates who took part in service-learning coursework during their undergraduate career differed in terms of initial post-graduation employment outcomes (i.e., how long it took to find their first job; starting salary; whether the job was in their area of interest; whether the employment was full-time vs. part-time; and whether and when employees received promotions and raises) compared to similar graduates without service-learning.

\section{Methodology Participants}

The study was designed to compare the employment outcomes of university alumni who were as similar as possible, except in regards to whether or not they had taken service-learning coursework. Thus, the initial participant pool was drawn from all undergraduate students who graduated from the University of Georgia (UGA) in calendar year 2010 with any major. The graduation year of 2010 was selected as being recent enough to be relevant, yet distant enough to determine actual job outcomes from respondents. The University of Georgia is a large, selective, public research university; its undergraduate enrollment in 2010 was just under 26,000 students, with about 6,500 bachelor's degrees conferred annually (UGA Office of Institutional Research, 2010). UGA is a land-grant institution and was designated a community engaged institution by the Carnegie Foundation in its 2010 review cycle. The university is located in Athens-Clarke County, Georgia, which had a population of about 116,000 in 2010 (http://quickfacts.census.gov/qfd/states/13/13059.html).

The university's Office of Service-Learning compiled a listing of undergraduate courses that incorporated service-learning pedagogy for a six-year period from fall semester 2004 through fall semester 2010. The 128 identified courses were from at least 48 departments, representing 12 of the 13 schools and colleges offering undergraduate coursework at the institution. While service-learning courses ranged from first-year learning communities to senior-level capstones, 75 of the 128 represented upperdivision (3000- to 4000-level) courses. Some 1,202 total course sections of service-learning classes were 
offered during this time frame. UGA's Office of Institutional Research then generated a listing of all students who graduated with a bachelor's degree in 2010. The office compiled individual information about these graduates and their demographics (e.g., gender, ethnicity, state of residence, overall grade point average, SAT scores, etc.) and, based on their course enrollment history, identified which students had taken any of the courses identified as incorporating service-learning during that timeframe.

An initial pool of potential survey participants was selected with the intent to create matched pairs from respondents. Thus, the overall list of graduates was first divided into groups based on who had and had not taken at least one identified service-learning class. Students were only included in the initial study sample population if there was at least one corresponding student from the opposite group with identical major and graduation date along with reasonably similar SAT score, undergraduate GPA, gender, and ethnicity.

Some 279 graduates from the list of those who had taken service-learning did not have any match generated from non-service-learning students in their same major and graduation date. (For instance, in some majors, all students may have taken a service-learning course or too few graduated in a particular semester to return a close match.) This group was used to pilot test the survey instrument (see next section). After eliminating students without either a mailing address or an email address on file with the university's Office of Alumni Records, a set of 1,324 potential participants who had taken servicelearning, and 670 additional alumni who could be matched to one or more of those in the service-learning condition, was created.

\section{Survey Instrument and Dissemination}

The survey instrument and roster of potential participants were entered into the university's online survey platform (Qualtrics) account, which created unique URLs for each potential participant. Because the alumni records office's data were not always up-to-date, two methods of recruitment were deemed important to boost participation: individualized emails were sent via Qualtrics to each potential participant with an email address on file, and a hardcopy of recruitment and consent information with a shortened alias URL was also mailed to all potential participants with a mailing address on file (about 75 of which were returned as non-deliverable). Both the pilot and main study were conducted with approval from and in accordance with the university's IRB guidelines, including informed consent from all participants.

Invitations to participate were sent first to the 279 graduates from the overall sample who had no match and would serve as a pilot group for the main survey; 64 (22.9\%) responded. After reviewing responses, the study instrument was finalized, and invitations to participate in the main study were sent to the 1,994 potentially matched participants during spring and summer 2013, with an additional email reminder via Qualtrics to those who had not responded during the first two weeks.

The online survey included several parts, though internal survey logic routed respondents to different sections depending on their responses. First, respondents indicated their graduation date and major. Next, they were asked to indicate whether, upon graduating, they sought employment, attended graduate/professional school, or did something else. For those who indicated that they sought immediate employment, the survey queried if they had ever been employed post-graduation and, if so, in what month and year they first became employed. Additionally, participants were asked if this job was in their "desired area of interest" and if the job was full-time or part-time. They were also asked to report the job's salary. To indicate their annual starting salary, respondents could either enter the actual dollar amount themselves, or could select from a list of salary ranges (from $\$ 10,000$ to $\$ 130,000$ ) in $\$ 2,000$ increments. They were then asked if they received a raise while working for this employer and, if so, when and how much, as well as if they received a promotion at the job and, if so, when.

Respondents were also given a short definition of academic service-learning and asked how many undergraduate service-learning courses they had taken. If they indicated having taken at least one such course, they were asked to select what impacts they perceived the service-learning course having on their employment (e.g., "Helped me decide on my choice of field"; "Helped me get a job"; "Helped me get a higher starting salary"; "Helped me get promoted faster"; "Helped me get a raise"; "Had no impact on my 
employment"). Participants were likewise asked what impact service-learning had on their post-graduate education. Finally, they were provided a section for additional open-ended comments for the researchers and were asked to re-confirm their willingness to have their responses included in the research study.

Four hundred forty-seven valid responses (of 568 total) were provided for the main study sample (22.4\% response rate). For the purposes of this study, respondents who reported attending graduate or professional school or otherwise not seeking employment directly after college were removed from the sample, leaving 276 respondents who sought immediate post-graduation employment-78 who had not taken service-learning courses, and 198 who had. Based on the student information provided by the university's Office of Institutional Research, the study participants were mostly female (54.7\%) and White (91.8\%), though other ethnicities were also represented (4.7\% Black, 2.9\% Asian, 2.2\% Hispanic). Their mean undergraduate grade point average (GPA) was 3.36 (SD, 0.41) and their mean composite SAT score was reported as 1237 (SD, 135). Most (88.4\%) graduated in May 2010 (spring semester), with the remainder graduating in August 2010. Of the 198 who had taken courses classified as service-learning, most (117, or about 59\%) had taken a single class; 55 had taken two courses, 18 had taken three, six had taken four, and one each had taken five or six service-learning classes during their undergraduate career.

\section{Data Analysis and Matching}

The participant response data were downloaded from Qualtrics into a spreadsheet file and merged with the original data provided by the Office of Institutional Research (e.g., gender, ethnicity, degree information, SAT scores, GPA, and number of service-learning courses taken). The data were then reviewed for accuracy and recoded for consistency and analysis. For instance, all time-based responses were converted into months (e.g., "time to first employment" was calculated based on the time that elapsed between a student's graduation month/year and the month/year reported for becoming hired). For those who selected a predefined range (in $\$ 2,000$ increments) of annual salary, the mean figure of that range was used, while the actual dollar amount was used for those reporting their annual salary as such. Additionally, some variables (such as ethnicity) were recoded into dummy variables for analysis. All analyses were conducted using STATA 12.0 .

Next, a matching process was created and run on the overall sample of all eligible respondents to create a set of unique, closely matched pairs for the analysis (i.e., no graduate was matched to more than one other respondent). A random search algorithm was used on all potential participant pairs to ensure that the final pairs selected had the smallest overall differences possible, thus creating the closest available match, with one member of each pair having had service-learning and the other member not. Because both undergraduate major (e.g., Koc, 2014; Pascarella \& Terenzini, 2005; Webber, 2014) and gender (e.g., Blau \& Kahn, 2007; Gerhart, 1990; Koc, 2014) seemed likely to have a strong potential influence on employment and earnings outcomes, the final algorithm required both members of any pair to be matched exactly, not only for the same graduation semester/year and the same major but also for gender. The algorithm then sought the best match within potential pairs for other variables of interest. Specifically, the sum of absolute differences in GPA across the members of the pair, differences in their SAT score (since this was a larger number, SAT score differences were multiplied by 0.25 within the algorithm), and differences/similarities in ethnicity (using dummy variables of White/non-White) determined how closely any potential pair of participants were matched. (To ensure the similarity of academic background, no proposed pairs were accepted if their GPA difference exceeded 0.8 or the verbal plus quantitative SAT difference exceeded 250 points; three potential pairs were returned for

which the best match still exceeded these differences and were subsequently eliminated. ${ }^{1}$ ) This resulted in a final sample of 44 unique, closely matched pairs for the analysis. Participants in these matched pairs represented some 20 unique majors, were almost all White (92\%), and were majority female (57\%). (By comparison, the university's overall 2010 undergraduate enrollment was $57.4 \%$ female and $77.2 \%$ White [UGA Office of Institutional Research, 2010]). Tables 1 and 2 provide additional information about the participants included in these matched pairs. 
Table 1. Descriptive Statistics for Respondents in Matched Pairs ( $\mathrm{n}=44$ in each group)

\begin{tabular}{|c|c|c|c|c|c|}
\hline Group & Gender & Ethnicity & Mean GPA (SD) & $\begin{array}{l}\text { Mean Composite } \\
\text { SAT Score (SD) }\end{array}$ & $\begin{array}{l}\text { Found Initial } \\
\text { Employment }\end{array}$ \\
\hline $\begin{array}{l}\text { Service- } \\
\text { Learning }\end{array}$ & $\begin{array}{l}19 \text { Male } \\
25 \text { Female }\end{array}$ & $\begin{array}{l}40 \text { White } \\
1 \text { Black } \\
1 \text { Asian } \\
2 \text { not reported }\end{array}$ & $3.45(0.38)$ & $1270(124)$ & $\begin{array}{l}41 \text { Yes } \\
\text { (3 part-time) }\end{array}$ \\
\hline $\begin{array}{l}\text { No Service- } \\
\text { Learning }\end{array}$ & $\begin{array}{l}19 \text { Male } \\
25 \text { Female }\end{array}$ & $\begin{array}{l}41 \text { White } \\
1 \text { Black } \\
1 \text { Multiracial } \\
1 \text { not reported }\end{array}$ & $3.43(0.35)$ & $1276(131)$ & $\begin{array}{l}42 \text { Yes } \\
\text { (6 part-time) }\end{array}$ \\
\hline
\end{tabular}

Table 2. Majors Represented by Participants in Matched Pairs

\begin{tabular}{lc}
\hline Major & Frequency \\
\hline Accounting & 1 \\
Art & 1 \\
Comparative Literature & 1 \\
Economics & 2 \\
English & 2 \\
Finance & 10 \\
History & 3 \\
International Affairs & 4 \\
Linguistics & 1 \\
Management & 3 \\
Marketing & 5 \\
Nutrition Science & 1 \\
Political Science & 1 \\
Psychology & 1 \\
Real Estate & 1 \\
Risk Management/Insurance & 1 \\
Social Studies Education & 1 \\
Spanish & 2 \\
Special Education & 1 \\
Speech Communication & 2 \\
TOTAL & 44 \\
\hline
\end{tabular}




\section{Research Questions and Hypotheses}

The overall research question was whether graduates who had taken service-learning courses had positive differences in initial employment-related outcomes when compared to their peers without service-learning experience. Specifically, the study tested the hypotheses that, when compared to those without servicelearning, participants with service-learning experiences would (1) be more likely to receive a full-time job after graduation; (2) be more likely to report a job in their preferred field; (3) receive a higher starting salary; (4) obtain their first job more quickly; (5) receive a raise more quickly, receive a higher-value raise, and be more likely to receive a raise; and (6) receive a promotion more quickly and be more likely to be promoted.

For the first two hypotheses, proportion tests were performed to detect possible differences in the share of graduates in each category who reported that their first job was in their desired field and that their first job was full-time. Proportion tests were also used to investigate (for hypotheses 5 and 6) potential differences in the percentage of respondents in each group who indicated that they received a raise or promotion at all. The final four hypotheses were tested via paired-sample t-tests on the difference in the means for each self-reported outcome variable of interest: starting salary; months from graduation to first employment; months from first employment to first raise (if any); amount of raise (if any); and months from first employment to first promotion (if any). All tests were one-tailed, in the direction favoring the service-learning participants' employment outcomes, with an exploratory $p$-value set at 0.10 for significance.

\section{Results}

Table 3 reports the results of the proportion tests, and Table 4 the paired t-tests, for the variables of interest by hypothesis. As the degrees of freedom suggest, the t-tests only compared matched pairs in which both members were employed (39 pairs), received a raise (16 pairs), reported the amount of raise received (10 pairs), or were promoted (6 pairs). Because the two groups differed significantly regarding the proportion of each group with a full-time job, and because this seemed likely to impact average salaries, the t-test on starting salaries was also run a second time, including only the 31 pairs in which both members of the matched pair reported full-time employment (Table 5). This allowed for a more directly matched comparison of starting salaries.

Effect sizes were calculated for significant t-test results, using Wiseheart's (2013) online effect size calculator for Cohen's $d$ with corrections for dependence between means. Overall, the results offer support in favor of the graduates with service-learning in terms of starting income, time to first raise, and receiving a full-time job (the first, third, and fifth hypotheses), but not for the other proposed benefits for job-seekers with service-learning experience. 
Table 3. Means, Standard Errors, and Proportion Tests Comparing Paired Samples $(n=39)$ with and without Service-Learning (SL)

\begin{tabular}{|c|c|c|c|c|}
\hline Hypothesis & Group & Mean (SE) & Z Statistic & P Value \\
\hline \multirow[t]{2}{*}{ 1. Proportion receiving a full-time job } & SL & $0.95(0.04)$ & $z=1.49$ & $0.068^{*}$ \\
\hline & No SL & $0.85 \quad(0.06)$ & & \\
\hline \multirow{2}{*}{$\begin{array}{l}\text { 2. Proportion reporting job in their } \\
\text { desired field }\end{array}$} & SL & $0.74(0.07)$ & $\mathrm{z}=0.98$ & 0.16 \\
\hline & No SL & $0.64 \quad(0.08)$ & & \\
\hline 5. Proportion receiving a raise at this & SL & $0.59(0.08)$ & $z=-1.44$ & 0.93 \\
\hline & No SL & $0.74 \quad(0.07)$ & & \\
\hline \multirow{2}{*}{$\begin{array}{l}\text { 6. Proportion receiving a promotion at } \\
\text { this first job }\end{array}$} & SL & $0.38(0.08)$ & $\mathrm{z}=0.00$ & 0.5 \\
\hline & No SL & $0.38(0.08)$ & & \\
\hline
\end{tabular}

Table 4. Means, Standard Deviations, Degrees of Freedom, and t-Statistics Comparing Paired Samples with and without Service-Learning (SL)

\begin{tabular}{|c|c|c|c|c|}
\hline Hypothesis & Group & Mean (SD) & T Statistic (df) & $P$ value \\
\hline 3. Starting salary (in dollars) & SL & $40,518(18,468)$ & $t=2.21(38)$ & $0.017 *$ \\
\hline & No SL & $33,987(13,908)$ & & \\
\hline 4. Time to first job (in & SL & $2.92(5.85)$ & $t=-1.24(38)$ & 0.11 \\
\hline & No SL & $4.92(7.45)$ & & \\
\hline 5. Time to first raise (in & SL & $8.75(5.34)$ & $t=-1.33(15)$ & $0.10^{*}$ \\
\hline & No SL & $11.31(5.23)$ & & \\
\hline Amount of raise (in & SL & $18,900(21,070)$ & $t=1.13(9)$ & 0.14 \\
\hline & No SL & $8,765(14,190)$ & & \\
\hline \multirow{2}{*}{$\begin{array}{l}\text { 6. Time to first promotion } \\
\text { (in months) }\end{array}$} & SL & $15.67(10.42)$ & $t=0.25(5)$ & 0.59 \\
\hline & No SL & $14.33(5.89)$ & & \\
\hline
\end{tabular}

${ }^{*} p<0.10$ (1-tailed) 
Table 5. Means, Standard Deviation, Degrees of Freedom, and t-Statistic Comparing Starting Salary for Full-Time Employed Paired Samples with and without Service-Learning (SL)

\begin{tabular}{lllll}
\hline Hypothesis & Group & Mean (SD) & T statistic (df) & P value \\
\hline 1. Starting salary (in dollars) & SL & $43,552(18,278)$ & $t=1.39(30)$ & $0.087^{*}$ \\
& No SL & $38,952(10,673)$ & & \\
& &
\end{tabular}

${ }^{*} p<0.10$ (1-tailed)

A larger share of graduates with service-learning experience reported obtaining full-time work in their first job than did those without service-learning (hypothesis 1), although no significant difference was found in the percentage of graduates in each group who reported that the positions were in their desired field (hypothesis 2). The reported starting salary (hypothesis 3) for graduates with service-learning experience was significantly higher than that of their paired counterparts, by an annual average of over $\$ 6,500$ (including those with both full- and part-time employment) or $\$ 4,600$ if only including those in each group with full-time work. For these starting salary differences, the effect size was $d=2.26$ (including both full- and part-time wages) or $d=1.48$ (full-time wages only).

While the overall average time to find a first job was about two months sooner for graduates with service-learning experience than for those without, this was highly variable and not statistically significant (hypothesis 4). In terms of impacts of service-learning on raises (hypothesis 5), although the share of graduates with service-learning coursework who reported receiving a raise at their jobs was no greater than their paired counterparts, those who did receive raises tended to do so significantly more quickly, receiving their raises about two and a half months faster than those without service-learning experience. The effect size for this difference was $d=1.33$. Although the mean raise amount reported by those with service-learning was more than twice as much as for those without service-learning, with only a small number of pairs (10) reporting the amount of their raises and a wide standard deviation, this apparent difference was not statistically significant. Likewise, regarding promotions (hypothesis 6), graduates with service-learning appeared no more likely to be promoted, nor to receive promotions more rapidly, than their counterparts without service-learning.

\section{Discussion}

The present study makes several contributions to deepening the understanding of service-learning's potential impacts. In particular, rather than relying upon assumptions about how service-learning experiences might indirectly shape employment outcomes (e.g., through influencing particular career preferences or fields), this study directly investigates associations between such experiences and outcomes including salary, time to attain employment, and type of work. Service-learning's status as a high-impact educational practice is based upon robust findings of academic benefits that include greater likelihood of degree completion (Lockeman \& Pelco, 2013) and better mastery of academic content (Warren, 2012); evidence also strongly suggests that service-learning experiences can positively influence participants' civic and personal outcomes across a range of variables (Clayton, Bringle, \& Hatcher, 2013). The present study, focusing on a different set of outcomes, also helps extend the field's knowledge base to better "map the role of within-college experiences on life after college," as Pascarella (2006, p. 516) has challenged.

This study also provides important baseline data for further investigating employment benefits associated with service-learning. "Given the importance of earnings in individual economic and social well-being, it is important to understand what educational determinants really matter to one's earning power in the labor market" (Hu \& Wolniak, 2010, p. 763). While not directly intended to test the University of Delaware team's hypotheses, the present study does provide some concrete data to crosscheck and ground the researchers' stated assumptions, potentially serving as a basis for future studies. For 
instance, the original projections posited by the University of Delaware investigators regarding lifetime earnings benefits for their university's Class of 2011 (Overby et al., n.d.) anticipated that 25\% of students who took service-learning courses would receive a $2 \%$ higher starting salary, that $20 \%$ of them would receive a job three months sooner, and that $15 \%$ would receive annual raises $0.5 \%$ higher than their peers without service-learning experiences (W. Latham, personal communication, May 3, 2012).

The present study's findings demonstrated a significantly higher mean starting salary for graduates with service-learning classes versus those without - in fact, much greater than hypothesized by Overby and her colleagues (n.d.), representing an $11.8 \%$ (for full-time job holders) or 19.1\% (including both fulland part-time wages) higher starting salary. No statistically significant differences appeared for the analysis of average time to gain first employment, so our data did not support this assumption. Those with service-learning who received raises did so more quickly than their counterparts (by over two months on average), but the small sample of those reporting raise amounts for both members of matched pairs in the current study did not allow a statistically significant validation of this hypothesis by the Delaware team. A higher proportion of our study's graduates with service-learning received full-time employment, which also had a substantive impact on the overall salaries earned.

Thus, without attempting to assign or confirm an overall lifetime economic impact of the servicelearning experience for graduates, the current study's results do indicate at minimum a starting benefit for those entering the job market with this experience. This suggests that hypotheses like those posited by the Delaware team are not necessarily unreasonable. Additional, longer term studies may help ascertain the actual lifetime earnings influences from any between-group differences in these employment outcomes. Whether a starting benefit actually translates into additional leveraging of economic value across an employee's career is uncertain. Students with service-learning experience did not report any benefit versus peers without this experience in terms of speed or frequency of promotion, nor did they have a higher overall rate of receiving raises, for instance. So, any observed impacts may actually be applicable to the initial entry into the job market and the first several months or so of employment; it is not clear whether these effects would continue to provide substantial influence after candidates have been in the workforce for some time.

Although service-learning experiences have been shown to influence career interest and choice, our study did not support the concern posited by some (e.g., Hu \& Wolniak, 2013) that service-learning may depress graduates' wages by leading them to disproportionately select lower paying (if civically rewarding) service careers. This interplay and its potential bi-directional influences would benefit from further research.

Finally, the reasons for any actual employment or economic advantage associated with servicelearning need to be investigated in more depth. For instance, do candidates perceive and/or use the experiences from their service-learning as strategic talking points or bargaining chips? Are applicants considered higher quality due to the practical experiences they have accrued and/or due to actual or presumed superior development of particular skills desired by employers (Sternberg, 2013)? Future research, including qualitative and mixed-methods designs, that investigates both employer and jobseeker attitudes and decision-making may help clarify any actual mechanisms by which service-learning experiences translate into higher salaries or faster job placement.

Given the high levels of interest among students, employers, and institutions of higher education (among other constituents) in "identify[ing] those factors that appear to be related to being successful in the job search" (Koc, 2014, p. 1) and in the overall potential impacts that starting salaries have on lifetime earnings, the present study's findings may help raise awareness of the influence that taking part in academic service-learning experiences may have. That is, service-learning experiences-in addition to their documented benefits on student academic and personal learning, degree completion, and civic outcomes - could also prove economically valuable, particularly for students choosing worthwhile but typically less lucrative paths. Such an association may influence decisions that students and advisors make in terms of coursework (for both required and optional classes), majors, and degrees. While college majors definitely play an "enormous role in determining college graduates' wages" (Carnevale, Cheah, \& 
Hanson, 2015, p. 5), other substantive influences also exist-including taking part in service-learning experiences - and should be part of any informed decision-making by all constituents.

\section{Limitations}

Several potential limitations from this study are also salient. Pascarella (2006) has noted that "because it seeks to identify potential causal relationships in natural settings, research on the impact of college on students is an extremely challenging area in which to work" (p. 517). First, as this was not a randomizedcontrol trial, the present study was not able to directly test whether the service-learning pedagogy itself resulted in the differences seen across groups. Because grouping was based on preexisting course selections, it is possible that other differences might underlie the observed outcomes. (So, for instance, one could hypothesize that a student with high levels of self-direction and motivation might both choose courses with service-learning opportunities, ${ }^{2}$ as well as better prepare for job interviews, without the former accounting for any employment-related differences.)

As with any study that relies on self-reported data from respondents, information such as starting salary, time to attain employment, etc., has not been independently verified and could be subject to biases or errors of memory or interpretation. While we asked respondents how many service-learning courses they had taken, we did not ask them to specify or name the course(s), instead relying on the institutionally created list of coursework, which Kolek (2013) has suggested can be a more accurate source of data but still may be incomplete or incorrect. While Fenzel and Peyrot (2005) found that service-learning's impacts on long-term attitudes varied based on level of quality of the service-learning course, in the present study no attempts were made to differentiate by course-level features such as reflection frequency or amount of service. Likewise, although respondents were asked to identify whether their initial job was in their area of interest, how respondents operationalized this is not known. Since the actual job title or discipline was not collected, the extent to which their employment was in fact related to respondents' major and/or to the particular service-learning course(s) they took, as well as whether their jobs were in "service-related" fields (e.g., Fenzel \& Peyrot, p. 26), was not investigated in this study.

This study is based on a snapshot of a single year's graduates and as such represents employment findings from a particular period in time (i.e., the "great recession"). While we believe that three years post-graduation is sufficient time to investigate outcomes relating to initial job placement, the particular economic and employment climate of this period from 2010 to 2013 may not be typical or necessarily applicable to other time periods. Also, many respondents reported that they continued to graduate school or otherwise did not initially seek employment, so were not included in the analysis. It is possible that any impacts of service-learning among this group would be different than for those who immediately sought employment after graduation; additional research specifically targeting this question would be helpful. Also, given that the current study focused on initial employment post-graduation, other longer term research would help clarify the longevity of the initial benefits.

Because of the need to match pairs, the potential pool of data was diminished due to non-response (or elimination of those who did not seek or find employment) from graduates in either category, reducing the sample size substantially from the initial pool and even further for subsequent specific analyses (e.g., of those receiving raises), limiting statistical power. (Since the recruitment letter characterized the study as investigating "long-term impacts from taking academic service-learning coursework," some potential participants may have decided that they did not have relevant data to contribute, but actual reasons for non-response are not known.) Another idiosyncrasy of the matched-pair methodology was that, if (for instance) all graduates of the same major in a single semester took a service-learning course, there were no other potential participants to match them to, thus eliminating that particular major from the analysis entirely. Although over 20 unique majors across a range of disciplines were represented in our final sample of matched pairs, respondents were neither a random nor a representative sample of all majors. Also, as all participants were from a single (large, public, land-grant, research) university situated in a particular region of the country (i.e., the southeastern U.S.), it is possible that results might vary based upon institutional type, size, or other characteristics; replication of this study by other institutions and with additional breadth of majors would help clarify the robustness of the current study's findings. 
Matching of pairs was made on key variables of hypothesized importance for employment outcomes such as major (Hu \& Wolniak, 2013; Koc, 2014; Webber, 2014), gender (Blau \& Kahn, 2007; Cohen \& Huffman, 2003), academic performance, and graduation date, but as mentioned previously, not all differences between respondent pairs were (or can be) controlled. For instance, although ethnicity, race, and/or socioeconomic status may play a role in job-related outcomes (Fernandez \& Fernandez-Mateo, 2006; Hu \& Wolniak, 2010; Koc, 2014; Pais, 2011), their contribution is not fully understood, and those factors were not specifically incorporated into our analysis. While equivalent ethnicity was included as a preference in the matching algorithm to create the paired samples, almost all respondents self-reported as White, limiting the potential investigation into this component. Other variables of potential interest, such as family socioeconomic background (Koc, 2014), participation in other relevant extracurricular or noncourse-based service activities (Hu \& Wolniak, 2010, 2013), internships, etc., were not investigated but could be included in future follow-up research to determine their impact on these employment outcomes as well.

\section{Conclusions}

This study has the potential to support university and student investment in service-learning coursework beyond the pedagogy's well-demonstrated impacts on students' academic learning, social, cognitive, and civic outcomes. Although education - and service-learning and community engagement in particularcannot and should not be reduced to a "dollars and cents" equation that overlooks the myriad human and personal development benefits of higher learning (Hu \& Wolniak, 2013; Perna, 2005), an awareness of factors that relate to employment outcomes can also help stakeholders (including students, parents, university administrators, and others) better understand the impacts of educational decisions and options.

This study's results represent the first data-driven estimates of potential job-related benefits associated with service-learning experiences. Several previously hypothesized employment outcomes associated with having taken service-learning classes were confirmed, while others were not supported by the current data. In particular, across the sample of pairs matched closely on major, graduation date, gender, and academic performance, the 2010 graduates who had taken service-learning coursework reported that they received higher starting salaries, received raises more quickly, and were more likely to have gained full-time employment in their first job than those without service-learning. These findings, representing a range of over 20 majors and a strong matched sample design, are expected to provide a starting point for other research that may help continue to clarify the long- and short-term economic and employment impacts affiliated with service-learning pedagogy for undergraduate students.

\section{Notes}

1. For the remaining participants, individual GPAs ranged from 2.42 to 3.95; within-pair differences ranged from 0.0 to 0.73 , with an average difference of only 0.02 in favor of the group with servicelearning. SAT scores ranged from 990 to 1560, with within-pair differences from 10 to 200 points, averaging a difference of only 5.9 points in favor of the group without service-learning.

2. However, recent end-of-semester surveys of students in service-learning coursework at the University of Georgia have indicated that over one-third of the respondents reported not knowing that the course included service-learning when they registered for it.

\section{Author Note}


Paul H. Matthews, Office of Service-Learning, University of Georgia; Jeffrey H. Dorfman, Agricultural and Applied Economics, University of Georgia; Xuedong Wu, Agricultural and Applied Economics, University of Georgia.

Xuedong $\mathrm{Wu}$ is now at Wells Fargo, Charlotte, NC.

\section{Correspondence}

Correspondence regarding this article should be addressed to Paul H. Matthews, Associate Director, Office of Service-Learning, University of Georgia, 1242 1/2 S. Lumpkin Street, Athens, GA 30602. Phone: (706) 542-0892. E-mail: pmatthew@,uga.edu

\section{References}

Astin, A. W., Vogelgesang, L. J., Ikeda, E. K., \& Yee, J. A. (2000). How service learning affects students. Higher Education. Paper 144. Retrieved from http://digitalcommons.unomaha.edu/slcehighered/144

Astin, A. W., Sax, L. J., \& Avalos, J. (1999). Long term effects of volunteerism during the undergraduate years. Review of Higher Education, 22(2), 187-202.

Blau, F. D., \& Kahn, L. M. (2007). The gender pay gap. The Economists'Voice, 4(4), 1-6.

Bringle, R., \& Hatcher, J. (1995). A service-learning curriculum for faculty. Michigan Journal of Community Service Learning, 2, 112-122.

Brownell, J. E., \& Swaner, L. E. (2010). Five high-impact practices: Research on learning outcomes, completion, and quality. Washington, DC: Association of American Colleges \& Universities.

Carnevale, A. P., Cheah, B., \& Hanson, A. R. (2015). The economic value of college majors. Georgetown University Center on Education and the Workforce. Retrieved from https:/cew.georgetown.edu/wp-content/uploads/Economic-Value-of-College-MajorsFull-Report-v2.compressed.pdf

Clayton, P. H., Bringle, R. G., \& Hatcher, J. A. (Eds.). (2013). Research on service-learning: Conceptual frameworks and assessment. Sterling, VA: Stylus.

Cohen, P. N., \& Huffman, M. L. (2003). Occupational segregation and the devaluation of women's work across U.S. labor markets. Social Forces, 81, 881-908.

Duncan, J., \& Taylor, T. B. (2013). Coming full circle: A guide to service-learning. San Diego: Cognella.

Eyler, J., \& Giles, D. (1999). Where's the learning in service-learning? San Francisco: JosseyBass.

Eyler, J. S., Giles, D. E. Jr., Stensen, C. M., \& Gray, C. J. (2001). At a glance: What we know about the effects of service-learning on college students, faculty, institutions, and communities, 1993-2000 ( ${ }^{\text {rd }}$ ed.). Washington, DC: Learn and Serve America, National Service Learning Clearinghouse.

Fenzel, L. M., \& Peyrot, M. (2005). Comparing college community participation and future service behaviors and attitudes. Michigan Journal of Community Service Learning, 12, 23-31.

Fernandez, R. M., \& Fernandez-Mateo, I. (2006). Networks, race, and hiring. American Sociological Review, 71, 42-71. 
Gerhart, B. (1990). Gender differences in current and starting salaries: The role of performance, college major, and job title. Industrial and Labor Relations Review, 43(4), 418-433.

$\mathrm{Hu}, \mathrm{S} .$, \& Wolniak, G. C. (2010). Initial evidence on the influence of college student engagement on early career earnings. Research in Higher Education, 51(8), 750-766.

Hu, S., \& Wolniak, G. C. (2013). College student engagement and early career earnings: Differences by gender, race/ethnicity, and academic preparation. The Review of Higher Education, 36(2), 211-233.

Jameson, J. K., Clayton, P. H., \& Ash, S. L. (2013). Conceptualizing, assessing, and investigating academic learning in service learning. In P. H. Clayton, R. G. Bringle, \& J. A. Hatcher (Eds.), Research on service learning: Conceptual frameworks and assessment. Volume 2a: Students and faculty (pp. 85-110). Sterling, VA: Stylus Publishing.

Koc, E. W. (2014). Factors associated with job-search success. NACE Journal. Retrieved from https://www.naceweb.org/j112014/factors-with-job-search-success.aspx

Kolek, E. A. (2013). Can we count on counting? An analysis of the validity of community engagement survey measures. International Journal of Research on Service-Learning and Community Engagement, 1(1), 92-108.

Kuh, G. D. (2008). High-impact educational practices: What they are, who has access to them, and why they matter. Washington, DC: Association of American Colleges \& Universities.

Lockeman, K. S., \& Pelco, L. E. (2013). The relationship between service-learning and degree completion. Michigan Journal of Community Service Learning, 20(1), 18-30.

McElhaney, K. A. (1998). Student outcomes of community service learning: A comparative analysis of curriculum-based and non curriculum-based alternative spring break programs. (Unpublished doctoral dissertation). University of Michigan, Ann Arbor, MI.

Newman, J. (2014, March 5). The pitfalls of comparing colleges based on postgraduate earnings. The Chronicle of Higher Education. Retrieved from http://chronicle.com/blogs/data/2014/03/05/the-pitfalls-of-comparing-colleges-based-onpostgraduate-earnings/

Overby, L. (2011, October). The economic impact of community engagement-University of Delaware. Poster presented at the $12^{\text {th }}$ Annual National Outreach Scholarship Conference, East Lansing, MI.

Overby, L. Y., Latham, W., Lewis, K., \& Serra, S. (n.d.). Is investment in student community engagement worthwhile? Measures of its economic impacts say, "yes. ” Unpublished manuscript, University of Delaware, Newark, DE.

Pais, J. (2011). Socioeconomic background and racial earnings inequality: A propensity score analysis. Social Science Research, 40, 37-49.

Pascarella, E. T. (2006). How college affects students: Ten directions for future research. Journal of College Student Development, 47(5), 508-520.

Pascarella, E. T., \& Terenzini, P. T. (2005). How college affects students: A third decade of research. San Francisco: Jossey-Bass.

Perna, L. W. (2005). The benefits of higher education: Sex, racial/ethnic, and socioeconomic group differences. The Review of Higher Education, 29(1), 23-52.

Sledge, A. C., Shelburne, M., \& Jones, R. (1993, November). Affective domain objectives in volunteer courses for postsecondary teachers. Paper presented at the Annual Meeting of the Mid-South Educational Research Association, New Orleans, LA. 
Smedick, W. D. (1996). A study of the effect of a volunteer service program at an urban-based institution of higher education on the current level of service achieved by alumni who had participated in the program. Unpublished doctoral dissertation, Morgan State University, Baltimore, MD.

Smith Korfmacher, K. (1999). Alumni perspectives on environmental service-learning: Implications for instructors. Michigan Journal of Community Service Learning, 6(1), 3852.

Sternberg, R. J. (2013, June 17). Giving employers what they don't really want. The Chronicle of Higher Education. Retrieved from http://chronicle.com/article/Giving-Employers-WhatThey/139877/

Tartter, V. C. (1996). City College report to FIPSE. New York: City College Research Foundation.

University of Georgia Office of Institutional Research. (2010). The University of Georgia fact book 2010. Athens, GA: Author. Retrieved from http://oir.uga.edu/eFactbook/2010/FactBook2010.pdf

Vogelgesang, L. J., \& Astin, A. W. (2000). Comparing the effects of service-learning and community service. Michigan Journal of Community Service Learning, 7, 25-34.

Warchal, J., \& Ruiz, A. (2004). The long-term effects of undergraduate service-learning programs on postgraduate employment choices, community engagement, and civic leadership. In Welch, M., \& Billig, S. (Eds.), New perspectives in service-learning research to advance the field (pp. 87-106). Greenwich, CT: Information Age Publishing.

Warren, J. L. (2012). Does service-learning increase student learning?: A meta-analysis. Michigan Journal of Community Service Learning, 18(2), 56-61.

Webber, D. A. (2014). The lifetime earnings premia of different majors: Correcting for selection based on cognitive, noncognitive, and unobserved factors. Labour Economics, 28, 14-23.

Wiseheart, M. (2013). Effect size calculator. Retrieved from http://www.cognitiveflexibility.org/effectsize/ 